\title{
Identifying Games as Consequences of Choice Behavior for Children
}

\author{
Beatriz Coletti do Sacramento \\ Federal University of São Carlos, São Carlos, SP, Brazil \\ Giovana Escobal ${ }^{1}$ \\ Celso Goyos \\ LAHMIEI Institute, Department of Psychology, Federal University of São Carlos, \\ São Carlos, SP, Brazil
}

\begin{abstract}
Social behavior may be defined as the behavior of two or more people with respect to one another or in concert with respect to a common environment. The aim of this study was to identify if pictures that represent games could function as social reinforcers for children. Participants were three children with typical development, and the experimental stimuli were two geometrical figures and pictures that represented games (apps) for a Tablet. Daily preference assessments were made, following the preference assessment. After selecting a geometrical figure, the participants were given the opportunity to engage in the game with one of the experimenters, represented in their favorite picture. The dependent variable was the percentage of times the participant chose a particular geometrical figure per session. The results suggest that the procedures used in this research were accurate to identify games as reinforcers and its reinforcing value was subsequently tested in simple discrimination and reversal tasks. This procedure can be conducted quickly and with a relatively low cost of response. This research demonstrated the importance of offering choice opportunities and contact with games for typical children, showing that games can be used as reinforcers for teaching procedures.
\end{abstract}

Keywords: Preference assessments, tablet applications, reinforcing value, children.

\section{Identificação de Jogos como Consequências de Comportamentos de Escolha para Crianças}

\section{Resumo}

O comportamento social pode ser definido como comportamento de duas ou mais pessoas, uma em relação à outra, ou em conjunto em relação a um ambiente comum. O objetivo deste estudo foi identificar se fotos que representam jogos poderiam funcionar como reforçadores sociais para crianças típicas. Os participantes foram três crianças com desenvolvimento típico, sendo os estímulos experimentais duas figuras geométricas, e fotos de jogos (aplicativos) para Tablet. Foram realizadas avaliações de preferência diárias, em seguida à avaliação de preferência, após selecionar uma das figuras geométricas, era dada aos participantes a oportunidade de engajar-se no jogo com um dos experimentadores, representado na foto de sua maior preferência. A variável dependente foi a porcentagem de vezes que

Mailing address: Federal University of São Carlos, Department of Psychology, LAHMIEI Institute, C.P. 676, São Carlos, SP, Brazil 13565-905. Phone: (16) 33518498, Fax (16) 33518361. E-mail: giovanaescobal@, hotmail.com

This manuscript was funded by Coordenação de Aperfeiçoamento de Pessoal de Nível Superior (CAPES). 
o participante escolheu um determinado formato geométrico por sessão. Os resultados sugerem que os procedimentos utilizados na presente pesquisa foram acurados para identificar jogos como reforçadores e seu valor reforçador foi testado posteriormente nas tarefas de discriminação simples e reversão. Esse procedimento pode ser conduzido de maneira rápida e com relativo baixo custo de resposta. A presente pesquisa demonstrou a importância em se oferecer oportunidades de escolha e oportunidades de contato com brincadeiras a crianças típicas, demonstrando que jogos podem ser usados como reforçadores em procedimentos de ensino.

Palavras-chave: Avaliação de preferência, aplicativos para tablet, valor reforçador, crianças.

\section{Identificación de Juegos como Consecuencias del comportamento de Selección para niños}

\section{Resumen}

El comportamiento social se puede definir como el comportamiento de dos o más personas con respecto a la otra, o conjuntamente, contra un entorno común. El objetivo de este estudio fue identificar si fotos que representan juegos podrían funcionar como refuerzos sociales para niños típicos. Los participantes fueron tres niños con un desarrollo típico, y los estímulos experimentales dos figuras geométricas, fotografías y juegos (aplicaciones) para la tableta. Evaluaciones diarias de preferencia se llevaron a cabo, siguiendo la evaluación de preferencia, después de seleccionar una de las figuras geométricas, se le dio a los participantes la oportunidad de participar en el juego con el experimentador 2, representada en la imagen de su mayor preferencia. La variable dependiente fue el porcentaje de veces que el participante eligió una forma geométrica determinada por sesión. Los resultados sugieren que los procedimientos utilizados en esta investigación fueron precisos para identificar los juegos como reforzadores y su valor de refuerzo se probó posteriormente en tareas de discriminación y de reversión de discriminación. Este procedimiento puede llevarse a cabo rápidamente y con costo de respuesta relativamente bajo. Esta investigación demostró la importancia de ofrecer oportunidades de elegir y oportunidades para jugar con los niños típicos, mostrando que los juegos pueden ser utilizados como refuerzos para los procedimientos de enseñanza.

Palabras clave: Evaluación de preferencia, applicaciones de tableta, valor reforzador, niños.

According to Keller and Schoenfeld (1950), social behavior can be described as behavior for which the reinforcing or discriminative stimuli are, or have been mediated by the behavior of another organism. By 'mediated', it is said to be 'in connection with'. According to the authors, then, social behavior would be relations subject to the environment in which the stimuli that constitute the behavioral relationships are mediated by others (Andery \& Sério, 2006).

According to Skinner (1953/1965), "social behavior may be defined as the behavior of two or more people with respect to one another or in concert with respect to a common environment" (p. 297). It is implicit in this definition that, in the case, the behavior of an individual is medi- ated by responses from another individual (i.e. that responses from this second individual assume stimulus functions - as stated by Keller and Schoenfeld, 1950).

Therefore, the responses from the two participants may be involved in a single contingency, possibly bounded by discriminative stimuli that evoke responses from each of them together, and by reinforcing stimuli, which are only produced if both emit the responses that are part of the contingency. In this contingency, the behavior of each participant operates as a discriminative stimulus or reinforcements for the behavior of the other one (Andery \& Sério, 2006).

Moreover, Sampaio and Andery (2010) point out Skinner's definition (1953/1965, 
1957/1992) of restricting social behavior to three-term contingencies whose consequences are produced by the operant behavior of another individual (i.e., the consequences are produced by an individual's action, however, there is mediation from another individual). According to the authors, social behavior would be «any three-term contingency whose consequences are mediated by the other one's behavior». Thus, the production of consequences not only involves operant behavior of the individual concerned, but also the operant behavior of a second individual who is mediating this consequence.

In addition to understanding the term used: «social behavior», it is important to talk about the three types of research developed by Behavior Analysis: Basic, Translational and Applied. The first, also known as Experimental Analysis of Behavior (EAB) was described by Poling (2010) as weak in the collective effort for a better social impact, adding that basic research studies are not relevant for significant actions of each individual in their natural environments. Moreover, EAB appears more often focused on the theory and basic principles than social problems (Critchfield, 2011).

Translational research is concerned with practical problems, however, it functions within the environment of convincing society that basic research deserves support. Moreover, this research is concerned with exploring the social relevance of a particular study without affecting the investigatorss ability of exploring theoretical problems. Therefore, one of the objectives of Translational research is to integrate basic science with their possible implications (Critchfield, 2011).

In practical terms, according to Baer, Wolf, and Risley (1968), Applied research shows the importance of behavioral change, as well as its quantitative characteristics, its experimental manipulations which analyze clearly what was responsible for behavioral change, the description of all the procedures that contributed to the change, and the effectiveness of these procedures, and finally, the ability to generalize this change.
As the applied research cannot do without scientific rigor and control variables, which differentiating it from basic research is not these aspects, but the social relevance of the relationship between the variables investigated.

Generally speaking, Translational research is designed as the exploration of factors that applied researchers can derive from basic science, and more clearly, Poling (2010) emphasizes the point about basic researchers bearing the responsibility of translational research by selecting research problems that directly target socially important problems.

Another relevant factor to the types of research and their correlations is due to the fact that basic researchers must understand the practical problems well enough to then decide which aspects of basic research and basic principles which are relevant to them. Collaboration with applied researchers is a good way for basic researchers to improve their translational thought (Mace \& Critchfield, 2010).

When we mix the previous ideas of social behaviors and types of research in Behavior Analysis, we show the importance of thinking about relevant procedures for such behavior. For example, for children who would present a deficit in social behavior, intervention focused on the individual using social and behavioral learning techniques could be considered (Cooper, Griffith, \& Filer, 1999), engagement in social behavior has been reported as an effective component of these types of interventions for many child disorders including childhood social phobia (Spence, Donovan, \& BrechmanToussaint, 1999) and specific learning abilities (Forness \& Kavale, 1999).

To make these interventions, identifying reinforcing stimuli is an important aspect for the effectiveness of programs designed to facilitate skill acquisition. In addition, the success of programs with positive reinforcement designed to minimize the occurrence of inappropriate behavior, could be effective only if such reinforcers used have reinforcing value. Furthermore, identifying these reinforcers, considered powerful, is a challenge. Most studies concerning identifying 
reinforcers have focused on: identifying potential reinforcers (e.g. preference assessments) without testing whether the stimulus can be used to increase the response; evaluating the reinforcing effects of the stimulus (e.g. evaluating reinforcers) without a procedure to say which specific stimulus would work as a reinforcer (Piazza, Fisher, Bowman, \& Blakeley-Smith, 1999).

Despite the immense benefits of offering choice opportunity, they are hardly included in educational procedures (Reid, Parsons, Green \& Browning, 2001). Thus, a useful procedure for this behavior is preference assessment, as the more knowledge about a person's preferences, the better the conditions to motivate him/her to successfully accomplish a task (Escobal, Macedo, Duque, Gamba, \& Goyos, 2010).

However, when mentioning preference assessment as an evaluation procedure of social behavior, an alternative form to carry out this procedure should be used. For example, representing certain games in pictures to carry out preference assessment. These games could then be matched with natural social episodes to reinforce social behavior acquisition. In the following section, some studies that were based on traditional methods to assess the preference of experimental subjects are discussed.

Conyers et al. (2002) conducted a study to assess how choice responses were influenced by different types of stimuli (objects, pictures and verbal descriptions). Choice opportunities were presented to nine individuals with intellectual disabilities in a preference assessment with paired stimuli. Each pair of items was presented to each participant in three conditions (tangible items, pictures of these items and the names) using a reversal design. First, the evaluation was conducted with edible items, and then with nonedible items.

The participants also did a test to measure their skills in simple and conditional discrimination tasks. They selected their favorite items consistently in terms of pictures and objects and their ability to make these choices was predicted with $94 \%$ accuracy for the discrimination skills. The findings suggest that the mode of stimuli can affect the accuracy of a preference assessment, and that the systematic review of basic discrimination skills can be used to predict the effectiveness of different methods for this population.

Groskreutz and Graff (2009) showed different results, in which the same items were evaluated in three different formats of preference assessment: tangible assessment with access to the item, assessment using pictures with access to the item, and assessment using pictures without access to the item. It should be mentioned that something important was done in this study; the experimenters tested the pairing between each picture and its corresponding tangible item, which may be a necessary skill when using any similar procedure (pictures instead of tangible items). It was also pointed out that in the first preference assessment session using pictures without access to the item, the participants behaved inappropriately. Moreover, one of the important results that the authors found was that when the results between the different formats of preference assessment are different, the assessment that includes access to the selected item is the best indicator of the actual reinforcing properties of the stimulus.

It is important to stress the importance of further studies that determine how to establish the choice opportunity as a reinforcer for individuals whose behavior does not seem to be affected by them. For example, the choice must acquire reinforcing properties after individuals are repeatedly exposed to choice and non-choice situations as follows: when the choice is available, the individual can obtain highly preferred items; when the choice is not available, the individual can obtain only non-preferred items. If the choice can be made as a reinforcer, teachers and clinics should provide an additional strategy to treat individuals with severe and profound disability. Furthermore, these findings show the importance of providing frequent choice opportunities to individuals (Lerman et al., 1997).

Nuernberger, Smith, Czpar, and Klatt (2012) investigated the preference for games ('horse ride', 'tip me', 'chase', 'spin', 'piggy', 'can't get up', 'tickles', 'timber', 'blast off', 'ready, 
steady, go', 'swing' and 'carousal') in three children with autism. Preference assessments were performed (in an alternative format) with multiple stimuli without replacement to determine a preference hierarchy for the game, followed by a reinforcer assessment. The parents and therapists were asked to identify which games each child preferred most. Then, photos were shown of the experimenter playing certain games with the child, and the child was asked to choose one. After each participant identified their favorite games, the reinforcer assessment was carried out whereby the participants were asked to perform simple tasks, such as putting two forks and two straws in the appropriate containers. Correct responses were reinforced by certain games in preference assessment made earlier. The results showed that different types of games functioned as reinforcers. In the study, only two reinforcing assessments were performed for each game, which may have affected their results. More reinforcing assessment sessions could make it possible to assess the response more accurately for each preferred game. In addition, only one preference assessment format was tested in this study.

Using computer resources can provide a more frequent use of preference assessments by more people, as well as more accurate and time-saving records. Snyder, Higbee and Dayton (2012) reported that videos, for example, can be an effective way to present social or complex stimuli in preference assessments. In their study, they assessed the correspondence between preference hierarchies generated from preference assessments with toys or videos of toys. Highly reinforcing items corresponded in two assessments for five out of the six participants, and items classified as low preference corresponded to four participants. The study focused on assessing the validity of video assessments, comparing the results with tangible assessments, and assessing the preference for toys instead of complex stimuli. The authors suggested that to evaluate the clinical usefulness of videos, future research could investigate its use with social or complex stimuli. They also point out that a con- sequence assessment was not carried out in their study to confirm if the stimuli identified as high preference functioned as reinforcers.

This research not only identified if computerized games represented by photographs functioned as reinforcers, but also tested the effectiveness of these games in simple and reversal discrimination tasks, and carried out a photogame matching phase, considered an important variable which influences the results when not performed. Thus, the aim of this study was to evaluate the reinforcing effects of high preference games (applications for a Tablet) represented by photos concerning the acquisition of simple reversal discrimination by children with typical development.

\section{Method}

\section{Participants}

Three children with typical development, aged four years old and a girl (Mariza) and two boys (André and Milton) participated in this study, recruited from a public school in the state of São Paulo. The names used for the participants are fictitious, following the ethics committee guidelines to which the research was subjected prior to its development. A prerequisite for participation was that the individuals were able to understand simple instructions (e.g., maintaining eye contact, looking when they were called, having choice behavior, etc.) and that they were not familiar with the preference assessment procedures. Data collection was carried out during the participants' semester.

\section{Ethical Procedure}

The ethical procedures, approved by the Ethics Committee of the Federal University of São Carlos, Process No. 21737813.6.0000.5504, Report No 469.136, informed consent and authorization (signed by the children's guardian), were followed.

\section{Place and Material Resources}

The research was conducted at the school where the participants were recruited in a room 
of approximately $3 \mathrm{~m} \times 4 \mathrm{~m}$ during the semester. A touch screen laptop computer with MestreLibras software (Elias \& Goyos, 2010), a Tablet, a table, a chair, paper, pens, record sheets, HP Premium Plus Photo Paper, a stopwatch, a camera and a camcorder were used. The MestreLibras software was used to schedule and manage the sessions, record and store the data.

\section{Experimental Stimuli}

Nine pictures corresponding to nine games (applications) for the Tablet were used. The pictures were in color and were $11 \mathrm{~cm}$ wide and 9 $\mathrm{cm}$ long (Table 1). [These stimuli were represented by $\mathrm{S}+$ throughout the research and used in the Familiarization steps (Stage II), Matching Task (Stage III) and Preference Assessment (Stage IV). A response was reinforced].

Table 1

Games from the Experiment and their Corresponding Figures

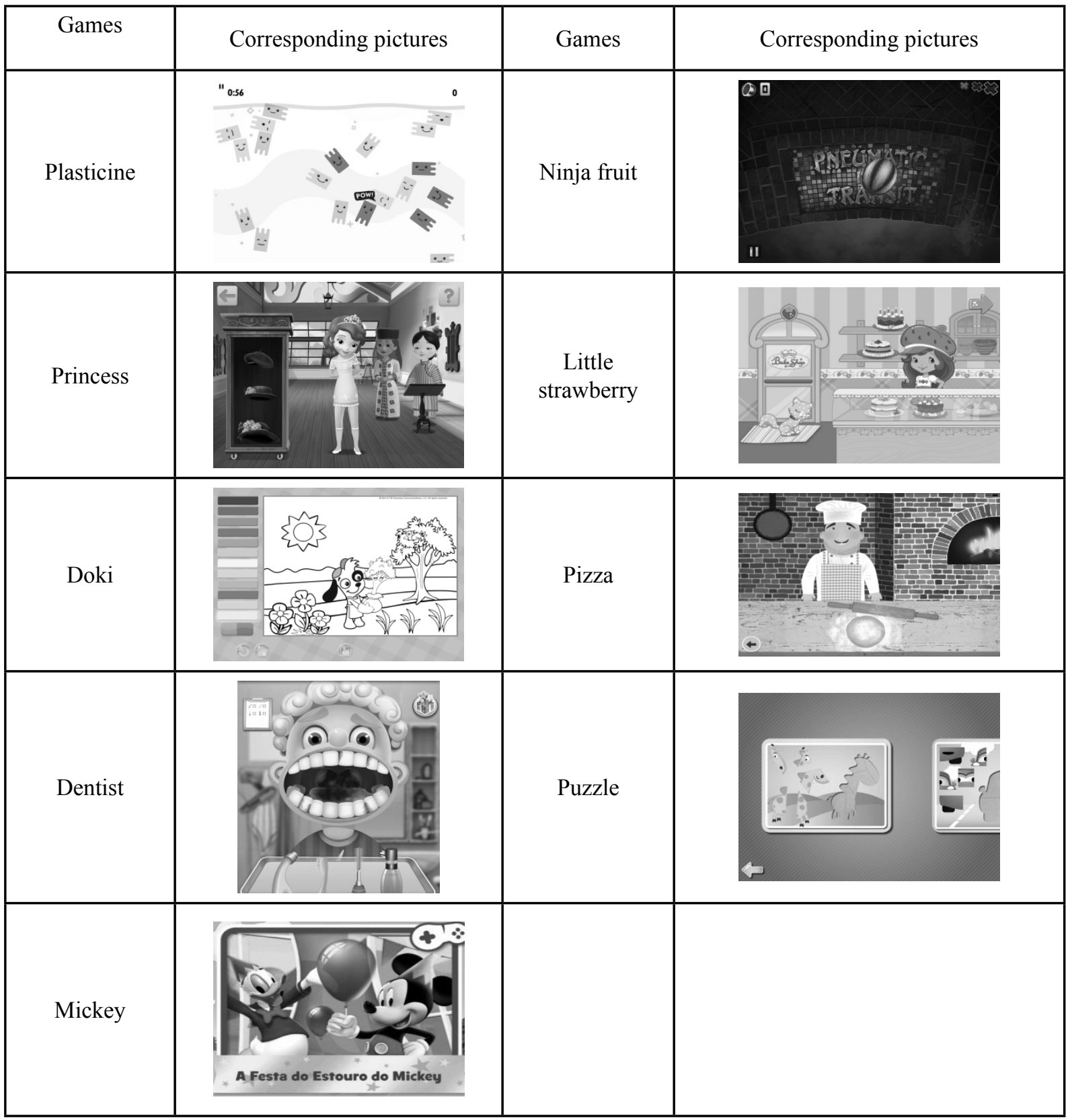


In addition, two experimental stimuli were used represented by geometric shapes of a circle and square, outlined in black on a white background, in the Joint Photographic Experts Group (JPEG; Table 2). [These stimuli were represented by $\mathrm{S}+$ and $\mathrm{S}$ - throughout the research and used in the simple discrimination and simple discrimination reversal stages - a test reinforcing the preference items (Stage V). In the presence of $\mathrm{S}+$, a response was followed by the games; in the presence of S-, the response was not followed by the games].

Table 2

Distribution of Experimental Stimuli used in the Simple Discrimination Task Involving Geometric Shapes

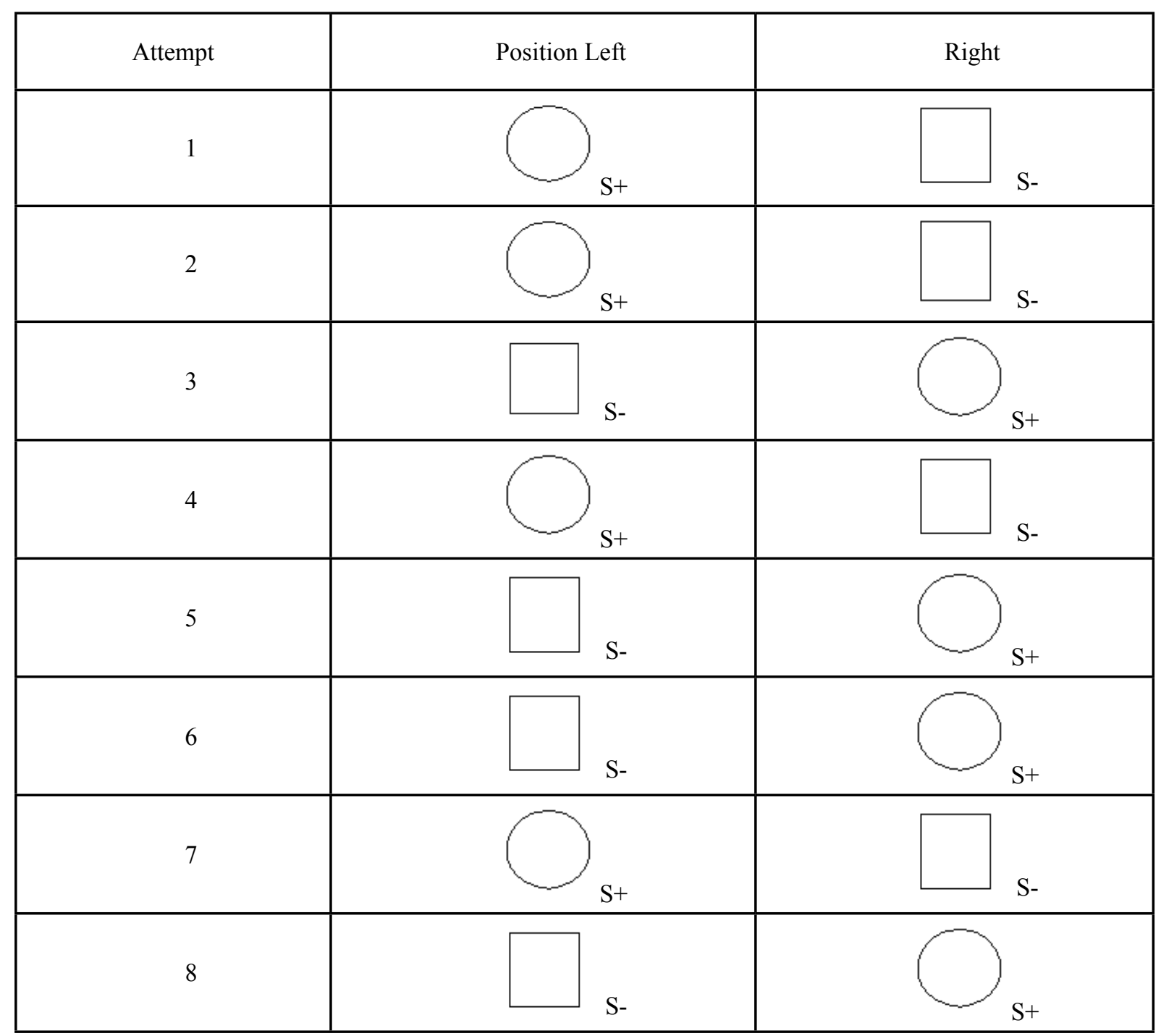




\section{Procedure}

The steps took place in the following order:

Table 3

Experimental Research Strategy

\begin{tabular}{|c|c|c|}
\hline $\begin{array}{l}\text { Experimental } \\
\text { stage }\end{array}$ & Stages & Function \\
\hline I & Interview & $\begin{array}{l}\text { Interview parents and teacher to find out which Tablet applications } \\
\text { were of interest to each participant. }\end{array}$ \\
\hline II & Familiarization & $\begin{array}{l}\text { Individual presentation of each picture that represented an applica- } \\
\text { tion so that the individual would have contact with the experimental } \\
\text { stimuli. }\end{array}$ \\
\hline III & Matching Task & $\begin{array}{l}\text { Provide more control concerning the picture-game matching by the } \\
\text { participant. The criteria to proceed to the next step was } 100 \% \text { of } \\
\text { correct answers. }\end{array}$ \\
\hline IV & Preference Assessment & $\begin{array}{l}\text { Assess which game was the participant's favorite one, so that it } \\
\text { could be used in the next step. }\end{array}$ \\
\hline $\mathrm{V}$ & $\begin{array}{l}\text { Reinforcer effect test } \\
\text { of the preferred items }\end{array}$ & $\begin{array}{l}\text { This step consists of evaluating the reinforcing value of the game } \\
\text { chosen as the high level preference in the Multiple Stimulus With- } \\
\text { out Replacement (MSWO) stage. }\end{array}$ \\
\hline
\end{tabular}

Interview. First, an interview was conducted with the parents and the participants' teacher to discover which Tablet applications were of interest to each participant out of nine options presented. Four were selected for each participant to then carry out the familiarization stage.

Familiarization. This step consisted of an individual presentation of each one of the four pictures representing an application by Experimenter 1 , and the name of the application shown in the picture was said at the same time followed by the activity lasting 15 seconds (using the application). The game was always played with Experimenter 2, as he/she played, and the next time the participant played. Two sessions of this step were held on two consecutive days, making a total of four familiarization sessions. This step was important for the subject to come into contact with the experimental stimuli.

Matching Task. This step was carried out so that there was more control with respect to the photo-game matching by the participant. It consisted of the participant playing with one of the games already used in the previous stage (familiarization), together with Experimenter 2. After
15 seconds of playing, the four pictures (chosen by parents and teachers in the interview stage) that represented the Tablet games were put on the table by Experimenter 1, followed by the question "which one did you play with?" and the child pointed to one of the pictures. This was done with the four games in two sessions per day, with four attempts each on two different days, making a total of four sessions for this step. The criteria to proceed to the next step was $100 \%$ correct answers.

Preference Assessment. One Preference Assessment with Multiple Stimulus Without Replacement (MSWO) was performed (Carr, Nicolson, \& Higbee, 2000; De-Leon \& Iwata, 1996), in which the four pictures representing the games (applications) on the Tablet were available on the table. Experimenter 1 said "Choose", the participant pointed to one of the pictures, and immediately received the game chosen for 15 seconds from Experimenter 2 (i.e. the participant played the game with the experimenter for 15 seconds). Experimenter 1 then recorded the response, removed the picture chosen by the participant, and rearranged the remaining 
three pictures on the table, giving the instruction again: "Choose". Again the chosen game (as a picture) was given by Experimenter 2 for $15 \mathrm{sec}$ onds. This was done until the participant chose each one of the four figures. The game, as a high preference level, was always the game represented by the picture that the participant chose first. This game was used in the next step. Only one preference assessment session was held on the first day after the previous steps prior to the first session of the Task discrimination.

Reinforcing Effect Test of Preference Items. This step evaluated the reinforcing value of the game chosen as a high level preference in the MSWO stage. This step consisted of Stage 1 and Stage 2. Each session comprised four attempts. Each attempt was started by presenting two stimuli together (the circle and the square on the computer screen), and each one of the stimulus was at the bottom left and right corners of the screen. The positions in which the stimuli were presented varied randomly throughout the attempts. Following the presentation of the stimuli, the oral instruction "Choose" was given. In Stage 1, responses to $\mathrm{S}+$ (circle), defined as the highest preference stimulus in the preference assessment test, were followed by 15 seconds of access of the game represented in the photo chosen as a high level of preference in the preference assessment test done previously, and responses to the S- (square) were followed by 15 seconds of a 'black screen' and the next attempt.

After reaching stability in the results in Stage 1, Stage 2 was conducted following the procedure similar to the previous stage, but there was a reversal of the stimulus, the $\mathrm{S}+$ is now represented by the choice in the square, and S-, the choice in the circle. The games provided after the choices in $\mathrm{S}+$, as well as in Stage 1 and Stage 2, were provided by Experimenter 2 .

Two to three sessions were held per day, on average for six days.

\section{Experimental Design}

We used an experimental design of a single subject (Smith, 2012), to verify if the games identified as high preference changed the percentage of choices in the choice task using dif- ferent geometric shapes. Intra and inter-subject comparisons were made (Tawney \& Gast, 1984).

\section{Procedure for Registration and Data Analysis and Reliability Calculation}

The data of interest were the choice responses in the competing schemes. For the choice behavior analysis, the dependent variable was the percentage of choice for each stimulus. The percentage was calculated by dividing the sum of the number of choices for each picture evaluated by the total number of choice opportunities in both evaluations. In addition, the number of correct responses was assessed in the choice tasks using different geometric shapes, as well as if the game had a reinforcing function, influencing the performance (measured by the parameter number of correct responses) in the task.

Data were collected based on the records of $100 \%$ of attempts, made by the computerized tool and protocols for observational recording of the choices - Record Sheet. These observations and records concerning the reliability calculation were made by the experimenter and an independent observer (or Experimenter 3), trained to carry out reliability testing. The reliability calculation was obtained by the formula: the number of agreements between the two observers, divided by the number of agreements plus disagreements, multiplied by 100 (Hall, 1974), and the result was $91.9 \%$.

\section{Results}

The results of each step of this experiment are described next.

\section{Familiarization and Matching Task}

Four familiarization sessions were held consisting of two sessions per day. Therefore, all the games from the list of each participant were presented to them, in a total of four times. The criteria for the Matching Task stage was $100 \%$ accuracy of the participants in the picture-game matching on the tablet. Four sessions were held, consisting of two sessions per day. All the participants reached the criteria in this stage. 


\section{Preference Assessment}

Only one preference assessment was carried out with Multiple Stimulus Without Replacement (MSWO) for each participant shortly after the Matching Task step. André was given the 'Fruit Ninja' game as a high level of preference and for Mariza and Milton, the game considered to be high-level preference was a 'Puzzle'.

\section{Assessment of the Reinforcing Effect of the Preference Items}

This step was taken to assess the reinforcing function of the stimuli. Two out of the three participants, André and Mariza, obtained the expected results according to the purpose of this study, because the stimuli used functioned as reinforcers in simple discrimination tasks (Figure 1).

In Stage 1, André received the 'Fruit Ninja' game for 15 seconds after the $\mathrm{S}+$ choice, and then 15 seconds of 'black screen', followed by the next attempt when he chose the S-. In five sessions of four attempts each, André showed a stable performance in $100 \%$ of the $\mathrm{S}+$ choices. In Stage 2, the discrimination reversal was introduced, and stability was shown in the results at $100 \%$ after two sessions.

For Mariza in Phase 1, eight sessions were held to reach stability of $100 \%$. The participant received the 'Puzzle' after choosing the $\mathrm{S}+$, and 15 seconds of 'black screen', plus the presentation of the next attempt, after choosing the SMariza had $50 \%$ of choices both in S + and S-, in the first two sessions, with $75 \%$ of choices in $\mathrm{S}$ + in the next three sessions. In the next sessions, she reached stability in the performance presenting $100 \%$ of choices in the $\mathrm{S}+$. In Stage 2, with the discrimination reversal, stability took place faster having three sessions of $75 \%$ of choices in the $\mathrm{S}+$, and $25 \%$ in the $\mathrm{S}-$, and then presented stability in the performance having $100 \%$ of S +choices in the four last sessions.

Concerning Milton, Stage 2 was not possible because it did not show stability of the data during Stage 1 of the experiment. The game used as a consequence for the choices in the $\mathrm{S}+$ was the 'Puzzle'. Therefore, when choosing the S+, he received 15 seconds of this game, and when choosing the S-, he received 15 seconds of 'black screen' followed by the presentation of the next attempt. This participant showed instability in their data, in the first three sessions, maintaining $50 \%$ of choices both in the $\mathrm{S}+$ and the S-. Based on Session 14, there was an increase in the number of attempts by sessions for this participant; instead of four attempts, twelve were made per session.

In Session 10, participants had $100 \%$ of choices in the S+, which was not maintained, with an unstable performance in Session 12 and Session 18 , showing a reduction in the choices for the $\mathrm{S}+$ in recent sessions. Considering the hypothesis that if there were more sessions, probably the choices in the $\mathrm{S}+$ would stabilize $0 \%$ of choices. This hypothesis cannot be proven because it was the end of the semester.

\section{Discussion}

Guided by the description given in the Introduction of the three types of research used in Behavior Analysis, it can be observed that in this study there is experimental rigor from basic research, with a setting similar to the laboratory, and concern about relevant behavior being performed in more natural conditions. In addition, the research was concerned with maintaining experimental, analytical and technological rigor, as well as presenting effective results and the possibility of generalizability.

When social consequence is considered as a conditioned reinforcer, social consequences could initially be paired with primary reinforcers until they acquire conditioned reinforcement value, and afterwards the primary reinforcers would be removed. This procedure could be carried out in future studies (Lerman et al., 1997). Using the Matching procedure most likely made the photos of the games acquire conditioned reinforcement value, as well as adding more reliability to the study, demonstrating the possibility of more control in translational and applied research. This is of utmost importance in interventions and applied research (Barnes, 1994; Barnes-Holmes \& Barnes-Holmes, 2000). 

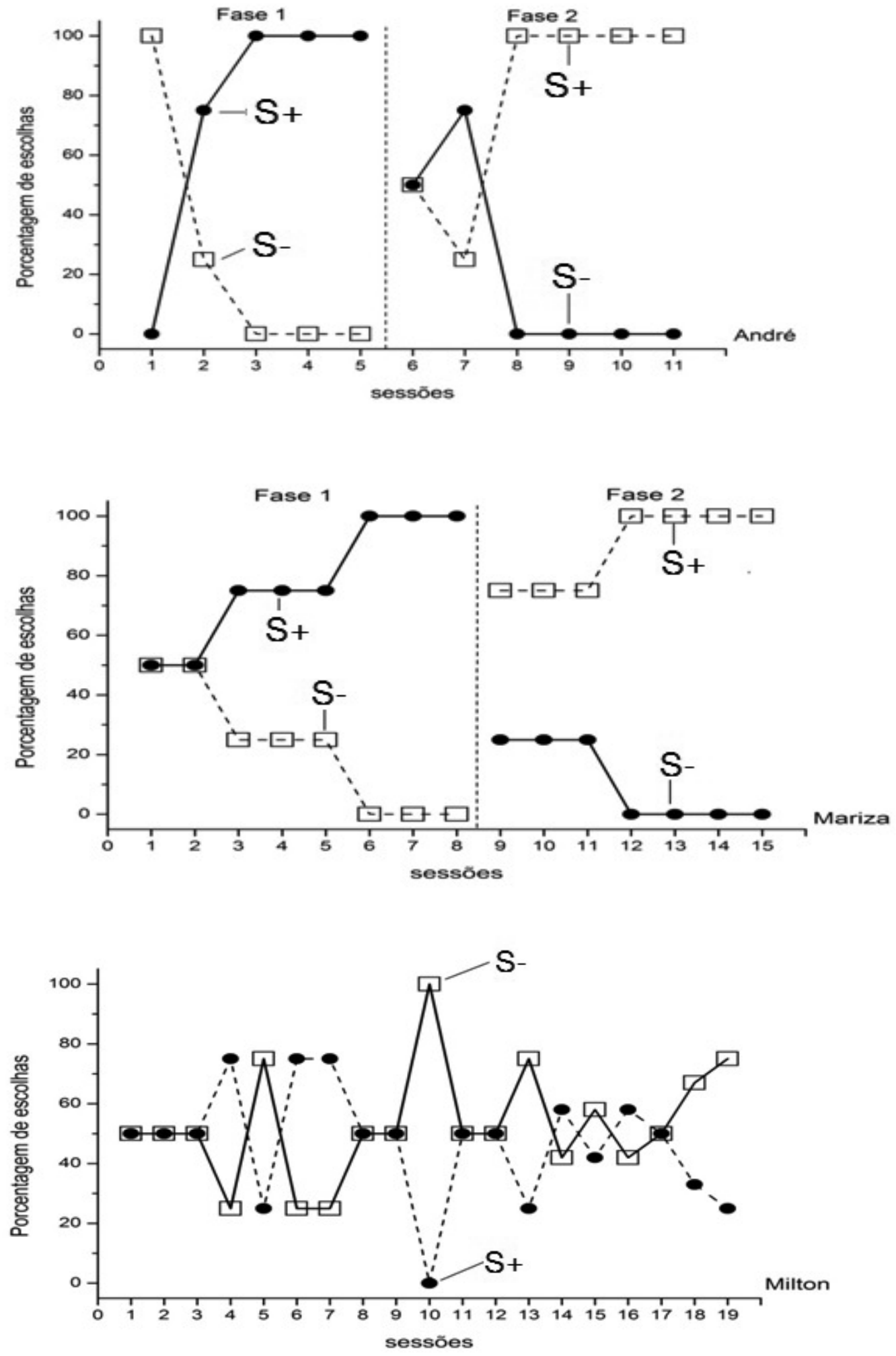

Figure 1. Percentage of choices from the participants: André, Mariza and Milton in the simple discrimination task involving different geometric shapes. White pictures represent choices in the $S$ - and black pictures represent choices in the $S+$ in Stage 1 . The white pictures represent choices in the $S+$ and black pictures represent choices in the $S$ - in Stage 2. 
In a study by Conyers et al. (2002), it was suggested that the mode of stimuli can affect the accuracy of a preference assessment, and that the systematic review of basic discrimination abilities can be used to predict the effectiveness of different methods for this population. In this study, the type of stimuli used seems to have been appropriate on the basis of the stability data in two out of the three participants in the Assessment stage of the reinforcing effect of the preferred items.

Groskreutz and Graff (2009) showed how relevant results (when the results between the different preference assessments) are different. The assessments that include access to the chosen item are the best indicators of the actual reinforcing properties of the stimulus. Groskreutz and Graff (2009) also pre-tested pairing skills between each picture and its corresponding tangible item, which may be a necessary skill to replace tangible items by pictures. In this study, a procedure was followed whereby the game was paired with their respective figures, which proved to be an important experimental control, as consistencies in the choices showed that the game and the picture can be taken from one another.

In addition, when choosing the picture in the preference assessment, the participant received the game from the experimenter, and not its corresponding picture, which proved to be important showing the real reinforcing properties of the stimulus. Higbee, Carr, and Harrison (1999) conducted a survey to determine the possibility of using pictures in preference assessments. In the evaluation with tangible items, each time the participant selected an item, he/she gained $20 \mathrm{~s}$ of access to this item. In the assessment with cards, however, the selection response did not result in access to the corresponding item. According to the authors, it is important to provide access to the item, as if access to the stimulus is designed as the reinforcer that maintains the selection response. Not providing access to the item would be similar to the extinction operation.

According to Vollmer and Hackenberg (2001), social consequences may be associated with unconditioned aspects. Unlike tangible items that can be delivered in a standardized way, the social consequences can appear in a variety of ways - facial expressions, social contacts, vocalizations - being released in different ways.

The biggest challenge is to find the characteristics that contribute to the effectiveness of the social consequences. Van Houten, Nau, Mackenzie-Keating, Sameoto and Colavecchia (1982) found that verbal reprimands were more effective in suppressing the problems when they were combined with physical and visual contact than only verbal reprimands alone. Kazdin and Klock (1973) found that smiles and physical contact increased the reinforcing effectiveness of verbal approvals in modifying the behavior of some students in the classroom. Therefore, when working with certain social behaviors, the procedure to be used should be completely developed, as well as the relevance of a Matching task when working with such consequences. Thus, the results obtained from a practical application can be observed, based on basic fundamentals of Behavior Analysis.

More studies should determine how to establish the choice opportunity as a reinforcer for individuals whose behavior does not seem to be affected by them. For example, the choice must acquire reinforcing properties after individuals are repeatedly exposed to choice and non-choice situations as follows: when the choice is available, the individual can obtain highly preferred items; when the choice is not available, the individual may obtain only non-preferred items. If the choice can be made as a conditioned reinforcer, teachers and clinics should provide an additional strategy for In addition, these findings highlight the importance of providing frequent choice opportunities to individuals (Lerman et al., 1997).

Regarding the indifference data from one of the participants, the possible contingencies can be discussed involving (a) the choice of the next task of the consequence "black screen", and (b) possible contingencies involving the alternative choice after the game (a) the lack of social contact may be part of the individual's 
history, often these participants may have little social contact with parents, relatives, etc. One possibility is that this previous experience could explain the choice of this alternative. Lee, Belfiore and Toro-Zambrana (2001) suggest that specific factors of the task, such as the history of working with a particular design, a particular way of the task and the importance between the different options of tasks can affect the selection of participants' behavior. That is, individuals can select the design option or task that most closely resembles a condition that they had in the past and which they already have some experience, as they often do not discriminate which condition results in higher reinforcement levels. An additional possibility is that the new conditions, represented by the alternative then the game, due to the novelty factor, and by demanding a different performance from the usual one, may include slightly aversive characteristics for participants who have a low tolerance to environmental changes. Thus, the choice would be controlled by negative reinforcement or 'exclusion'; (b) The first sharper choices may be due to the 'new task' factor. The participants could not be discriminated between the alternatives, therefore, to evaluate the effects of the type of reinforcer and its magnitude in the conditions studied, it would be necessary, for example, to emphasize these characteristics of the alternatives. In addition, the motivational variables of the participants could be tried to be identified and/or manipulated [(e.g., satiation and deprivation; Michael, 1993). Individuals could be deprived /satiated of certain stimuli (e.g., reinforcer videos) for specified periods to evaluate the effects of manipulation of motivational variables when using reinforcer videos, in the acquisition of simple and reversal discrimination)]; (c) To promote discriminability between the alternatives, procedures involving delayed reinforcement or different reinforcement durations could be included (Hanna \& Blackman, 2005), or discriminative training could even be carried out before the choice procedure (Escobal \& Goyos, 2015; Kodak, Lerman, Volkert, \& Trosclair, 2007); (d) In this study, the average latency performance was not measured in the alternatives during the assessment of preference for tasks. Future studies could assess this measure, as the average latency performance can influence the choice. The same can occur with the duration of the consequence and the 'black screen'. For example, for certain participants who consider social contact with the reinforcer experimenter, performances carried out in higher latency time /duration of consequence can be chosen. For the participant who wants to get rid of an aversive stimulus, the task, for example, could be considered aversive or even the very presence of the experimenter. Therefore, future studies could evaluate the social consequence to be more reinforcing by having less contact, if it is not the reinforcer.

\section{Conclusions}

Highlighting some positive points of the study: the idea that reinforcers are most effective when the individual is deprived of them was highlighted again in this study. If the participant obtained many reinforcers in the recent past, it is possible that he/she is satiated, and if this happens, this reinforcer will not be very effective to motivate this individual. Using a computerized tool to carry out the reinforcing value assessment of the preference items (MestreLibras) showed a different way to perform preference assessment refining the methodology, as well as having inserted the daily MSWOs before each assessment session of the reinforcing value, to increase the probability of the reinforcer item selection at that time.

Concerning the social behavior and procedures of this study, Skinner, 1953/1965, defines "social behavior as the behavior of two or more people with respect to one another or in concert with respect to a common environment". In this study, the children played with the experimenter on the Tablet and not alone. In the games presented in this study, one attempt was made by the participant and one by the experimenter. The performance of an individual depended on the performance of the other so that there was continuity in the game. Thus, this research stimulated in children behaviors to choose, waiting their 
turn to share an item and interacting socially; all fundamental to the repertoire of any individual. The methodology promoted the interrelationship between different areas of knowledge (Psychology, Special Education and Informatics) and produced a set of interventions enabling a new way of planning using applications for the Tablet with children.

\section{References}

Andery, M. A. P. A., \& Sério, T. M. A. P. (2006). Comportamento Social. In J. H. Guilhardi \& N. C. E. Aguirre (Eds.), Sobre comportamento $e$ cognição: Expondo a variabilidade. (pp. 124132). Santo André, SP: ESETec.

Baer, D. M., Wolf, M. M., \& Risley, T. R. (1968). Some current dimensions of applied behavior analysis. Journal of Applied Behavior Analysis, 1,91-97. doi:10.1901/jaba.1968.1-91

Barnes, D. (1994). Stimulus equivalence and relational frame theory. The Psychological Record, 44, 91-124.

Barnes-Holmes, D., \& Barnes-Holmes, Y. (2000). Explaining complex behavior: Two perspectives on the concept of generalized operant classes. The Psychological Record, 50, 251-265.

Carr, J. E., Nicolson, A. C., \& Higbee, T. S. (2000). Evaluation of a brief multiple-stimulus preference assessment in a naturalistic context. Journal of Applied Behavior Analysis, 33, 353-357. doi:10.1901/jaba.2000.33-353

Conyers, C., Doole, A., Vause, T., Harapiak, S., Yu, D. C. T., \& Martin, G. L. (2002). Predicting the relative efficacy of three presentation methods for assessing preferences of persons with developmental disabilities. Journal of Applied Behavior Analysis, 35, 49-58. doi:10.1901/ jaba.2002.35-49

Cooper, M. J., Griffith, K. G., \& Filer, J. (1999). School intervention for inclusion of students with and without disabilities. Focus on Autism and Other Developmental Disabilities, 14, 110115. doi:10.1177/108835769901400207

Critchfield, T. S. (2011). Translational contributions of the experimental analysis of behavior. The Behavior Analyst, 34, 3-17.

De-Leon, I. G., \& Iwata, B. A. (1996). Evaluation of a multiple-stimulus presentation format for assessing reinforcer preferences. Journal of Applied
Behavior Analysis, 29, 519-533. doi:10.1901/ jaba.1996.29-519

Elias, N. C., \& Goyos, C. (2010). MestreLibras no ensino de sinais: Tarefas informatizadas de escolha de acordo com o modelo e Equivalência de Estímulos. In E. G. Mendes \& M. A. Almeida (Eds.), Das margens ao centro: Perspectivas para as políticas e práticas educacionais no contexto da educação especial e inclusiva (pp. 223-234). São Carlos, SP: Junqueira \& Marin.

Escobal, G., \& Goyos, C. (2015). Trabalho de indivíduos com atraso no desenvolvimento intelectual: Contribuições da Análise do Comportamento Aplicada (ABA) e Processos de Tomada de Decisão. São Carlos, SP: Editora da Universidade Federal de São Carlos.

Escobal, G., Macedo, M., Duque, A. L., Gamba, J., \& Goyos, C. (2010). Contribuições do paradigma de escolha para identificação de preferências por consequências reforçadoras. In M. M. C. Hübner, M. R. Garcia, P. R. Abreu, E. N. P. De Cillo, \& P. B. Faleiros (Eds.), Sobre comportamento e cognição (pp. 371-376). Santo André, SP: ESEtec.

Forness, S., \& Kavale, K. (1999). Teaching social skills in children with learning disabilities: A meta-analysis of the research. Learning Disability Quarterly, 19, 2-13. doi:10.2307/1511048

Groskreutz, M. P., \& Graff, R. B. (2009). Evaluating pictorial preference assessment: The effect of differential outcomes on preference assessment results. Research in Autism Spectrum Disorders, 3, 113-128. doi:http://dx.doi.org/10.1016/j. rasd.2008.04.007

Hall, R. V. (1974). Managing behavior - behavior modification: The measurement of behavior. Lawrence, KS: H \& H Enterprises.

Hanna, E. S., \& Blackman, D. E. (2005). Escolha entre atrasos e durações diferentes de Reforço: Sobre a generalização de preferências em tentativas discretas para um procedimento de operante livre. Revista Brasileira de Análise do Comportamento, 1, 81-95. doi:http://dx.doi. org/10.18542/rebac.v1i1.764

Higbee, T. S., Carr, J. E., \& Harrison, C. D. (1999). The effects of pictorial versus tangible stimuli in stimulus-preference assessments. Research in Developmental Disabilities, 20(1), 63-72.

Kazdin, A. E., \& Klock, J. (1973). The effect of nonverbal teacher approval on student attentive behavior. Journal of Applied Behavior Analysis, 6(4), 643-654. doi:10.1901/jaba.1973.6-643 
Keller, F. S., \& Schoenfeld, W. N. (1950). Principles of Psychology. New York: Appleton-CenturyCrofts.

Kodak, T., Lerman, D. C., Volkert, V. M., \& Trosclair, N. (2007). Further examination of factors that influence preference for positive versus negative reinforcement. Journal of Applied Behavior Analysis, 40, 25-44. doi:10.1901/jaba.2007.151-05

Lee, D. L., Belfiore, P. J., \& Toro-Zambrana, W. (2001). Programming for efficiency: The effects of motion economy on vocational tasks for adults with severe and profound mental retardation. Research in Developmental Disabilities, 16, 205-220. doi:10.1016/0891-4222(95)00009-C

Lerman, D. C., Iwata, B. A., Rainville, B., Adelinis, J. D., Crosland, K., \& Kogan, J. (1997). Effects of reinforcement choice on task responding in individuals with developmental disabilities. Journal of Applied Behavior Analysis, 30, 411422. doi:10.1901/jaba.1997.30-411

Mace, F. C., \& Critchfield, T. S. (2010). Translational research in behavior analysis: Historical traditions and imperative for the future. Journal of the Experimental Analysis of Behavior, 93, 293312. doi:10.1901/jeab.2010.93-293

Michael, J. (1993). Establishing operations. The Behavior Analyst, 16, 191-206.

Nuernberger, J. E., Smith, C. A., Czpar, K. N., \& Klatt, K. P. (2012). Assessing preference for social interaction in children diagnosed with autism. Behavioral Interventions, 27, 33-44. doi:10.1002/bin.1336

Piazza, C. C., Fisher, W. W., Bowman, L. G., \& Blakeley-Smith, A. (1999). Identifying and assessing reinforcers using choice paradigms. In P. M. Ghezzi, W. Williams, \& J. E. Carr (Eds.), Autism: Behavior analytic perspectives (pp. 101-107). Reno, NV: Context Press.

Poling, A. (2010). Looking to the future: Will behavior analysis survive and prosper? The Behavior Analyst, 33, 6-17.

Sampaio, A. A. S., \& Andery, M. A. P. A. (2010). Comportamento social, produção agregada e prática cultural: Uma análise comportamental de fenômenos sociais. Psicologia: Teoria e Pesquisa, 26(1), 83-192. Retrieved from http://www. scielo.br/pdf/ptp/v26n1/a20v26n1
Skinner, B. F. (1965). Science and human behavior. New York: Free Press. (Original work published 1953)

Skinner, B. F. (1992). Verbal behavior. Acton, MA: Copley. (Original work published 1957)

Smith, J. D. (2012). Single-Case Experimental Designs: A systematic review of published research and current standards. Psychological Methods, 17, 510-550. doi:10.1037/a0029312

Snyder K., Higbee, T. S., \& Dayton, E. (2012). Preliminary investigation of a video-based stimulus preference assessment. Journal of Applied Behavior Analysis, 45(2), 413-418. doi:10.1901/ jaba.2012.45-413

Spence, S. H., Donovan, C., \& Brechman-Toussaint, M. (1999). Social skills, social outcomes, and cognitive features of childhood social phobia. Journal of Abnormal Child Psychology, 108, 211-221. doi:10.1037/0021-843X.108.2.211

Reid, D. H., Parsons, M. B., Green, C. W., \& Browning, L. B. (2001). Increasing one aspect of self-determination among adults with severe multiple disabilities in supported work. Journal of Applied Behavior Analysis, 34, 341-344. doi:10.1901/jaba.2001.34-341

Tawney, J. W., \& Gast, D. L. (1984). Single subject research in special education. Columbus, $\mathrm{OH}$ : Charles E. Merril.

Van Houten, R., Nau, P. A., Mackenzie-Keating, S. E., Sameoto, D., \& Colavecchia, B. (1982). An analysis of some variables influencing the effectiveness of reprimands. Journal of Applied Behavior Analysis, 15(1), 65-83. doi:10.1901/ jaba.1982.15-65

Vollmer, T. R., \& Hackenberg, T. D. (2001). Reinforcement contingencies and social reinforcement: Some reciprocal relations between basic and applied research. Journal of Applied Behavior Analysis, 34, 241-253. doi:10.1901/jaba.2001.34-241
Received: 29/03/2016

$1^{\text {st }}$ revision: $23 / 08 / 2016$

$2^{\text {nd }}$ revision: $31 / 08 / 2016$

$3^{\text {rd }}$ revision: $1 \% 09 / 2016$

Accepted: 02/09/2016 